\title{
ANÁLISE MICROESTRUTURAL DE UM AÇO INOXIDÁVEL DUPLEX UNS S32304 SUBMETIDO AO PROCESSO DE SOLDAGEM GMAW*
}

\author{
Thales Renó Grilo 1 \\ Rodrigo Pinto Siqueira ${ }^{2}$ \\ Gisele da Silva Arruda ${ }^{3}$ \\ Jefferson Fabrício Cardoso Lins $^{2}$
}

\section{Resumo}

O presente trabalho teve como objetivo analisar as diferentes microestruturas do aço inoxidável duplex UNS S32304 obtidas pelo processo de soldagem Gas Metal Arc Welding (GMAW). As regiões do metal base, zona fundida e zona afetada pelo calor foram investigadas nos corpos de prova com diferentes aportes térmicos. As microestruturas obtidas foram caracterizadas utilizando-se a microscopia óptica (MO). As imagens de Mo obtidas na zona afetada pelo calor mostram que a fração de austenita aumentou com o aumento do aporte térmico. Este aumento está relacionado ao alto teor de cromo e molibdênio presentes no metal de adição utilizado na soldagem. Na zona fundida, a fração de austenita de widmansttaten foi observada com maior frequência na microestrutura do corpo de prova soldado com o aporte térmico de $1,87 \mathrm{KJ} / \mathrm{mm}$. Essa maior fração de austenita de widmansttaten observada para o aporte térmico de $1,87 \mathrm{KJ} / \mathrm{mm}$ está relacionada com o maior tempo de permanência em altas temperaturas deste corpo de prova em relação aos outros corpos de prova investigados. Vale ressaltar que a adição de nitrogênio também promove a formação desta fase. De modo geral, os resultados da metalografia quantitativa mostram que a porcentagem de ferrita foi superior a $65 \%$ nas zonas termicamente afetadas e fundidas.

Palavras-chave: Aços inoxidáveis duplex; Soldagem; GMAW; Fase sigma; Microestrutura.

\section{MICROSTRUCTURAL ANALYSIS OF A DUPLEX STAINLESS STEEL UNS S32304 SUBMITTED TO GMAW WELDING PROCESS.}

\section{Abstract}

The microstructures of the duplex stainless steel obtained by the Gas Metal Arc Welding (GMAW) were evaluated. The base metal, fusion zone and the heat-affected zone were investigated in the samples with different heat inputs. The microstructures were characterized using light microscopy (LM). The LM images obtained in the heat-affected zone shows that the austenite volume fraction increased with the heat input increase. This increase is related to high contents of the chromium and molybdenum present in the filler metal used in welding. The fusion zone, the widmansttaten austenite volume fraction was observed more frequently in the microstructure with heat input of $1,87 \mathrm{KJ} / \mathrm{mm}$. This higher widmansttaten austenite volume fraction with the heat input of $1,87 \mathrm{KJ} / \mathrm{mm}$ is related to the higher cooling time at high temperatures in this sample in relationship to the others investigated samples. It is noteworthy that the addition of nitrogen also promotes this phase. In general, the results of the quantitative metallography showed that the percentage of ferrite was greater than $65 \%$ in the heataffected and fusion zones.

Keywords: UNS 32304; Welding microstructure; GMAW; Sigma-phase; Microestruture.

1 Mestrando em engenharia metalúrgica, Engenheiro metalúrgico, Programa de pós-graduação em engenharia metalúrgica, Universidade Federal Fluminense (UFF), Volta Redonda, RJ, Brasil.

2 Doutor em engenharia de materiais, Engenheiro de materiais, Programa de pós-graduação em engenharia metalúrgica, UFF, Volta Redonda, RJ, Brasil.

3 Graduando em engenharia metalúrgica, UFF, Volta Redonda, RJ, Brasil. 


\section{INTRODUÇÃO}

Os aços inoxidáveis duplex (AID) foram introduzidos no mercado durante a década de 1930. Nas duas últimas décadas, seu uso tem se tornado muito frequente em diversos setores industriais [1]. Com interesse de manter a resistência à corrosão localizada equivalente aos aços inoxidáveis austeníticos AISI 304L e 316L e reduzir o custo com relação aos AID, foram desenvolvidos os aços inoxidáveis lean duplex (AILD). Vale ressaltar que estes aços possuem teores reduzidos de molibdênio e níquel. Dentre esses aços AILD, o mais comumente utilizado é o UNS S32304. Diversas aplicações dos AILD foram reportadas na literatura [2], tais como, em tanques de estocagem na indústria de papel e celulose,na indústria offshoree também em tanques de armazenamento de alimentos.

Os aços inoxidáveis duplex têm sido recentemente atraídos pelo grande interesse devido a sua combinação de economia de custos e propriedades desejadas para este aço tais como alta resistência mecânica, à corrosão localizada, à abrasão e ao desgaste. Essas propriedades dependem de uma microestrutura formada pelas fases ferrita e austenita em proporções praticamente iguais. Isso resulta em uma significativa quantidade de elementos de liga, bem como um baixo teor de carbono. Dependendo da quantidade dos elementos de liga presentes no aço AILD e do tratamento térmico aplicado, pode-se precipitar diferentes fases tais como sigma $(\sigma)$ e Chi $(X)$ entre outras. Estas fases precipitam preferencialmente na ferrita, pois a difusão de elementos de liga na ferrita é cerca de 100 vezes maior do que na austenita, sendo a fase sigma o precipitado mais importante [3]. As fases $\sigma$ e a fase Chi que podem precipitar durante a conformação a quente ou também em operações de soldagem são as mais indesejáveis, pois podem causar sensitização no aço. A fase sigma pode precipitar entre as temperaturas de $600^{\circ} \mathrm{C}$ e $1000^{\circ} \mathrm{C}$ [4]. A manutenção de quantidades próximas de fases ferrítica e austenítica é muito importante na soldagem desses aços AILD. Para isso, o controle do aporte térmico é bastante desejável. A literatura recomenda que o aporte térmico esteja entre os valores de $0,5 \mathrm{KJ} / \mathrm{mm}$ e $2,5 \mathrm{KJ} / \mathrm{mm}$ para a soldagem dos aços inoxidáveis duplex em geral [5].

Neste contexto, Aguiar e colaboradores [6] fizeram um comparativo da fração volumétrica das fases ferrita e austenita utilizando a técnica de difração de elétrons retroespalhados (EBSD) com o objetivo de caracterizar a microestrutura especialmente a sua morfologia e a constituição do aço inoxidável lean duplex. Estes resultados foram comparados com outros resultados obtidos usando a técnica de microscopia óptica.

A soldabilidade dos aços inoxidáveis duplex é considerada inferior ao dos aços inoxidáveis austeníticos. Em geral a maior parte do problema da soldabilidade dos aços duplex resultam da redução da quantidade da austenita particularmente na zona fundida, na zona afetada pelo calor e precipitação de nitretos $[7,8,9]$.

No presente trabalho teve por objetivo analisar e quantificar as fases presentes nas amostras soldadas via GMAW com o metal de adição OK Autrod 2509 com aporte térmico dentro da faixa especificada entre 0,5 e $2,5 \mathrm{KJ} / \mathrm{mm}$.

\section{MATERIAIS E MÉTODOS}

Neste trabalho, o material utilizado foi o aço inoxidável duplex UNS S32304 fornecido gentilmente pela Aperam South America na condição laminado a quente. Os corpos de prova (4 unidades) foram confeccionados no formato de chapas com 
dimensões de $60 \times 150 \times 9 \mathrm{~mm}$. Em cada corpo de prova foi utilizado o processo de soldagem GMAW variando o aporte térmico com simples deposição sobre a chapa sem utilização de chanfro.

A composição química do aço UNS S32304 utilizado neste trabalho pode ser observada na Tabela 1. Neste trabalho foi utilizado o metal de adição OK Autrod 2509 da marca ESAB de diâmetro de 1,2mm. A Tabela 2 apresenta a composição química do metal de adição.

Tabela 1. Composição química do AID UNS S32304 (\% em peso)

\begin{tabular}{|c|c|c|c|c|c|c|c|c|c|c|c|c|}
\hline $\mathrm{C}$ & $\mathrm{Mn}$ & $\mathrm{Si}$ & $\mathrm{P}$ & $\mathrm{Cr}$ & $\mathrm{Ni}$ & $\mathrm{Mo}$ & $\mathrm{Cu}$ & $\mathrm{Co}$ & $\mathrm{V}$ & $\mathrm{Nb}$ & $\mathrm{Sn}$ & $\mathrm{W}$ \\
\hline 0,0 & 1,34 & 0,3 & 0,0 & 22,5 & 3,5 & 0,25 & 0,4 & 0,0 & 0,0 & 0,0 & 0,9 & 0,0 \\
17 & 9 & 56 & 25 & 58 & 72 & 9 & 24 & 36 & 33 & 14 & 93 & 10 \\
\hline
\end{tabular}

Tabela 2. Composição química do metal de adição (\% em peso)

\begin{tabular}{|c|c|c|c|c|c|c|c|}
\hline $\mathrm{C}$ & $\mathrm{Mn}$ & $\mathrm{Si}$ & $\mathrm{Cu}$ & $\mathrm{Cr}$ & $\mathrm{Mo}$ & $\mathrm{Ni}$ & $\mathrm{W}$ \\
\hline$<0,02$ & 0,40 & 0,40 & $<0,3$ & 25,0 & 4,00 & 9,80 & $<1,0$ \\
\hline
\end{tabular}

O gás de proteção utilizado foi o $\mathrm{Ar}-\mathrm{CO}_{2}-\mathrm{N}_{2}$ de composição química patenteada pela White Martins/Praxair. Para todos corpos de prova foi utilizado a mesma vazão de gás.

Os corpos de prova soldados com os diferentes aportes térmicos podem ser observados na Figura 1.

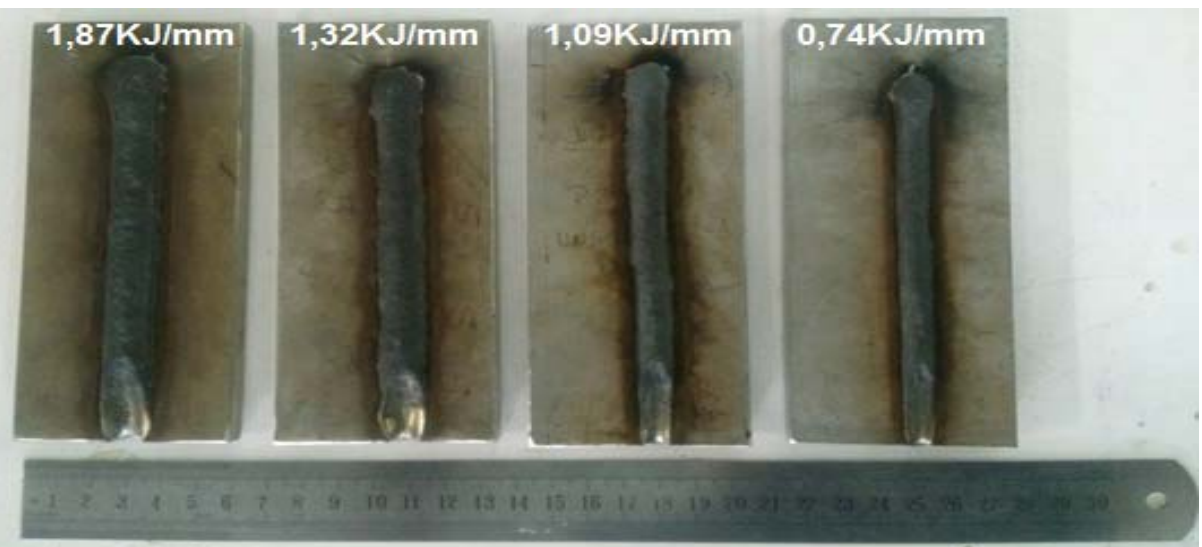

Figura 1. CPs soldados com aporte térmico de $1,87 \mathrm{KJ} / \mathrm{mm}, 1,32 \mathrm{KJ} / \mathrm{mm}, 1,09 \mathrm{KJ} / \mathrm{mm}, 0,74 \mathrm{KJ} / \mathrm{mm}$.

Os parâmetros de soldagem, corrente (A) e voltagem em Volts (V) foram mantidos constantes. A velocidade de soldagem variou com o intuito de produzir um aporte térmico desejado. Estes parâmetros são apresentados na Tabela 4.

Tabela 4. Parâmetros de soldagem utilizados.

\begin{tabular}{|c|c|c|c|c|}
\hline $\begin{array}{l}\text { Corpo de } \\
\text { prova }\end{array}$ & \multicolumn{1}{l}{$\begin{array}{l}\text { Corrente } \\
(\mathrm{A})\end{array}$} & $\begin{array}{l}\text { Voltagem } \\
(\mathrm{V})\end{array}$ & $\begin{array}{l}\text { Velocidade } \\
(\mathrm{mm} / \mathrm{s})\end{array}$ & $\begin{array}{l}\text { Aporte } \\
(\mathrm{KJ} / \mathrm{mm})\end{array}$ \\
\hline 1 & 310 & 32 & 5,3 & 1,87 \\
\hline 2 & 310 & 32 & 7,5 & 1,32 \\
\hline 4 & 310 & 32 & 9,1 & 1,09 \\
\hline 8 & 310 & 32 & 13,4 & 0,74 \\
\hline
\end{tabular}


Ao término da soldagem, uma amostra de cada corpo de prova foi retirada. Essas amostras foram preparadas metalograficamente utilizando-se uma lixadeira/politrizEcomet 250 da Buehler com a sequência de lixas: 200, 320, 500, $600,800,1000,1200,2400$ (mesh). Em seguida, o polimento das amostras foi feito utilizando-se a politriz rotativa da marca Struers com pasta de diamante na sequência: $6 \mu \mathrm{m}, 3 \mu \mathrm{m}, 1 \mu \mathrm{m}$ e posteriormente realizou-se o polimento com sílica coloidal. Com as amostras devidamente polidas, o ataque químico por imersão foi realizado utilizando a solução BEHARA II. O tempo de imersão das amostras foi de 10s. O exame metalográfico foi feito em um no microscópio óptico da marca LeitzMetallovert. A fração volumétrica das fases foi determinada seguindo a norma ASTM E562 utilizando o programa de análise de imagens marca Image-Pro Plus. Cada medida representa a média de 25 campos amostrados utilizando a ampliação de 500 vezes para as amostras do metal base, zona fundida e zona termicamente afeta exceto para a zona termicamente afeta da amostra com aporte térmico de $0,74 \mathrm{KJ} / \mathrm{mm}$ que foi utilizado 1000 vezes.

\section{RESULTADOS E DISCUSSÃO}

A Figura 2 apresenta a micrografia do metal na condição inicial laminado a quente. A micrografia mostra uma região do metal base na qual os grãos estão dispostos de forma alongada na direção de laminação (DL). A microestrutura é formada por grãos lamelares de ferrita (fase escura) e de austenita (fase clara) dispostos alternadamente. Esta amostra na condição inicial foi utilizada para efeito de comparação com as outras amostras soldadas. Podemos observar que as lamelas de austenita não são contínuas devido ao processo de laminação.

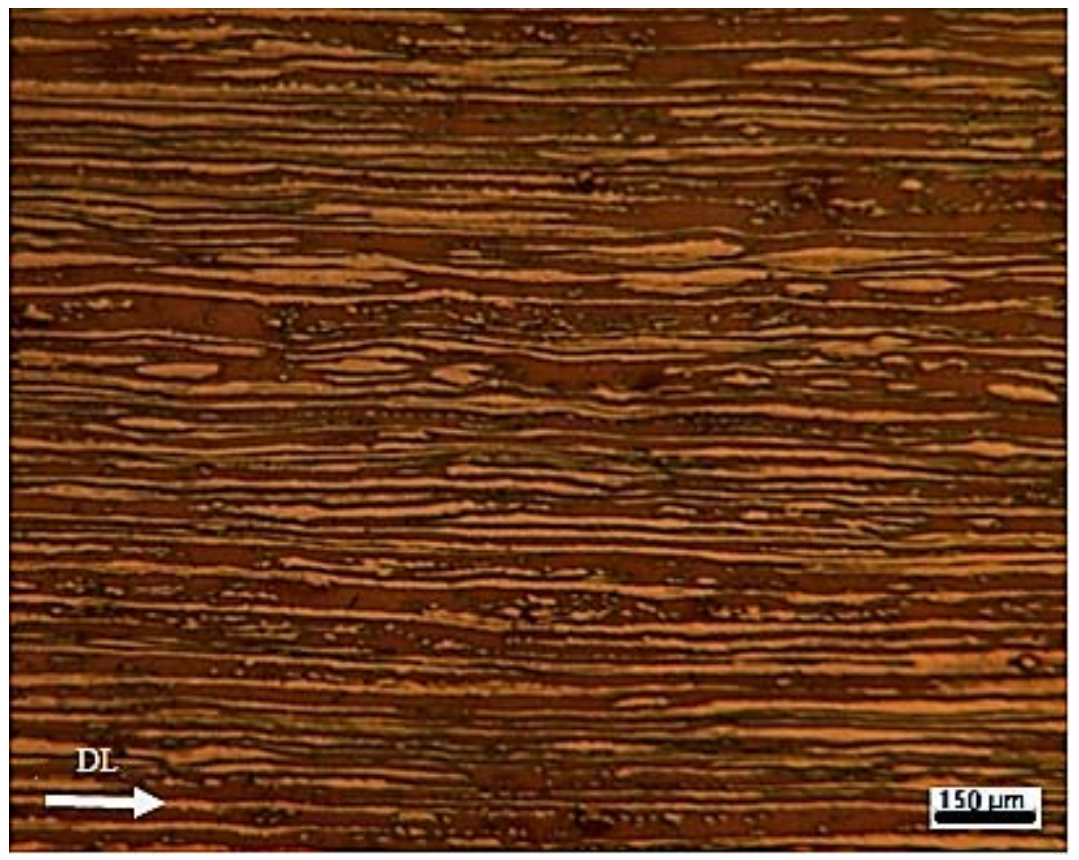

Figura 2. Microestrutura do metal base. A seta indica a direção de laminação (DL).

As frações volumétricas de austenita e de ferrita foram obtidas. O valor de fração volumétrica determinado foi muito próximo do encontrado na literatura, o valor de $57 \pm 4 \%$ para a ferrita e de $42 \pm 4 \%$ para a austenita [6]. Para a zona fundida, as frações volumétricas de austenita e de ferrita determinadas para os diferentes aportes térmicos são mostrados na Tabela 5. 
Tabela 5. Fração volumétrica de ferrita e austenita das amostras soldadas com diferentes aportes térmicos na zona fundida.

\begin{tabular}{|c|c|c|}
\hline $\begin{array}{c}\text { Aporte } \\
\text { térmico }(\mathrm{KJ} / \mathrm{mm})\end{array}$ & Austenita & Ferrita \\
\hline 0,74 & 17,1 & 82,9 \\
\hline 1,09 & 18,2 & 81,8 \\
\hline 1,32 & 20,1 & 79,9 \\
\hline 1,87 & 25,5 & 74,5 \\
\hline
\end{tabular}

Com o aumento do aporte térmico, pode-se observar que a fração volumétrica de austenita aumenta significativamente devido ao maior tempo de resfriamento. A amostra com aporte térmico de $1,87 \mathrm{KJ} / \mathrm{mm}$ permanece por um tempo mais longo nas temperaturas entre 1300 e $1400^{\circ} \mathrm{C}$. Esta faixa de temperatura promove a transformação da ferrita em austenita [7].

$\mathrm{Na}$ Figura 3 podemos observar as micrografias da zona fundida das amostras soldadas com diferentes aportes térmicos de $1,87 \mathrm{KJ} / \mathrm{mm}, 1,32 \mathrm{KJ} / \mathrm{mm}, 1,09 \mathrm{KJ} / \mathrm{mm}$ e $0,74 \mathrm{KJ} / \mathrm{mm}$.

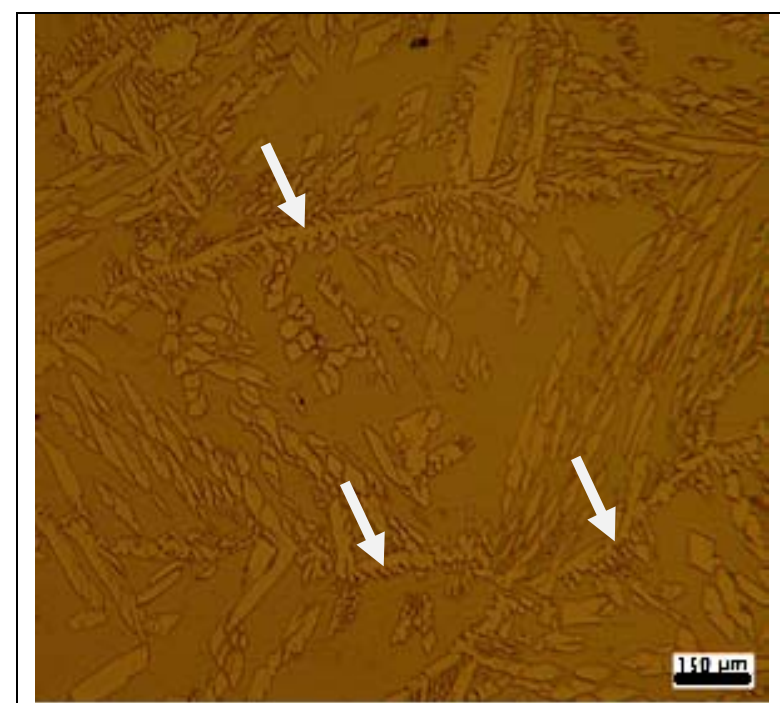

(a)

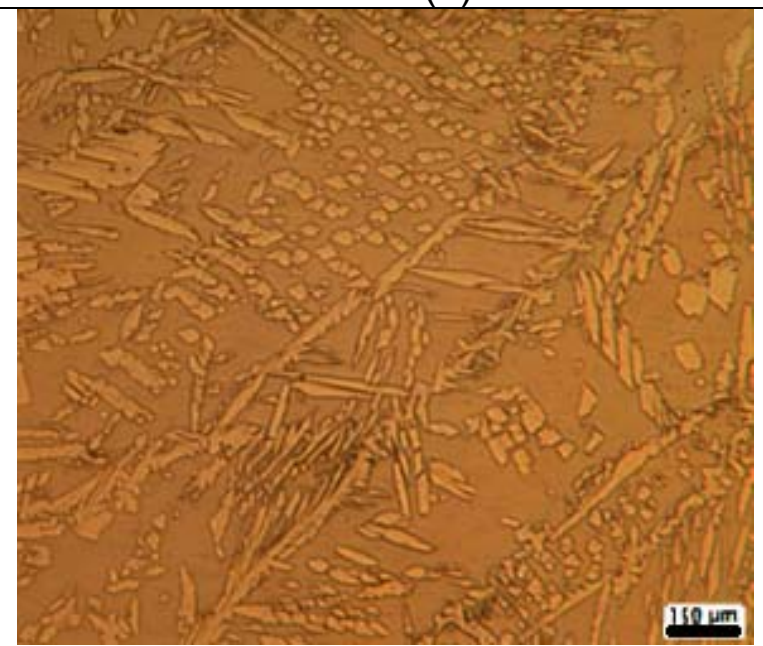

(b)

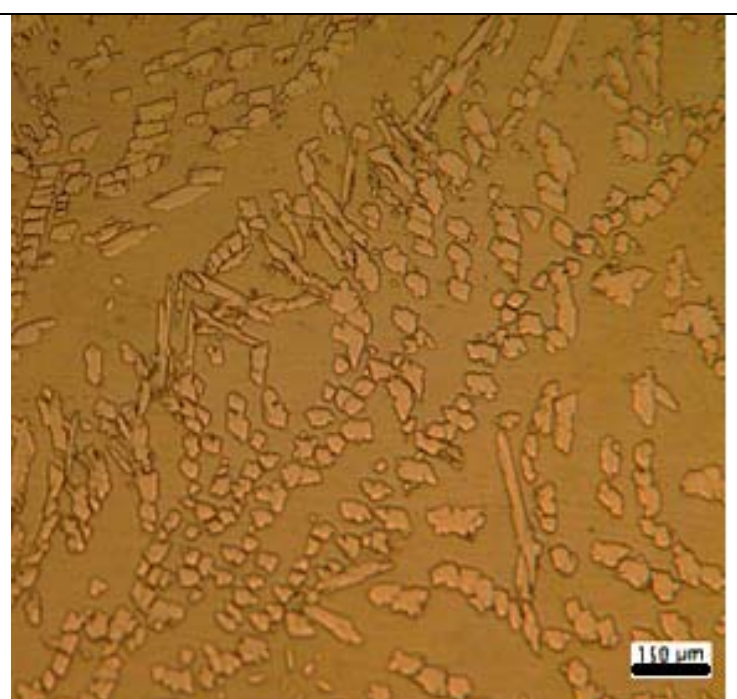

(c)

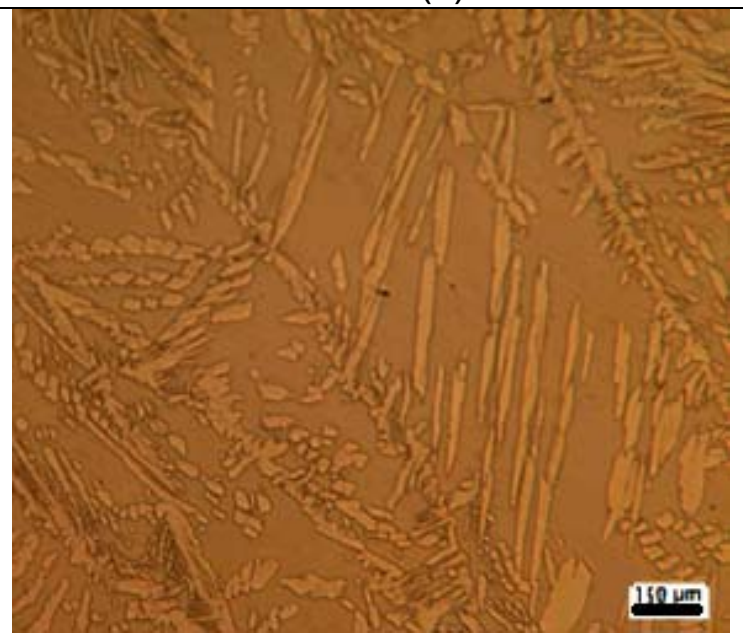

(d)

Figura 3. Microestrutura da zona fundida das amostras com aporte térmico de $1,87 \mathrm{KJ} / \mathrm{mm}(\mathrm{a})$, $1,32 \mathrm{KJ} / \mathrm{mm}(\mathrm{b}), 1,09 \mathrm{KJ} / \mathrm{mm}(\mathrm{c})$ e $0,74 \mathrm{KJ} / \mathrm{mm}$. 
$\mathrm{Na}$ soldagem, as propriedades mecânicas estão diretamente relacionadas com a microestrutura formada na zona fundida. Como esse aço contém elementos ferritizantes e austenitizantes, a solidificação pode-se iniciar tanto da formação da austenita como da ferrita delta. A transformação de fase é um fenômeno cuja nucleação heterogênea requer um substrato[10].

$\mathrm{Na}$ literatura, verificou-se que a adição de nitrogênio juntamente com aporte térmico elevado proporcionou uma maior formação de ferrita de Widmanstätten, pois o tempo de permanência em altas temperaturas é maior de modo que a adição de nitrogênio facilita a formação de ferrita de Widmanstätten [11,12].

Com o aumento do aporte térmico, a precipitação da fase austenita mais alongada com morfologia de widmansttaten foi ainda maior, como indicado por setas na micrografia da Figura 3. Esta fase pode ser nucleada tanto na interface entre grãos ferríticos e austeníticos como também pode ser formada a partir da austenita alotriomórfica formada no contorno de grão da ferrita [8,9]. Vale ressaltar que na zona fundida, o valor percentual da fase ferrita esteja na faixa de 35 a $65 \%$, de modo a aliar boa resistência à corrosão e boas propriedades mecânicas [13]. Quando os teores estão excessivamente altos de ferrita, a fragilidade pode ocorrer. Todos os aportes térmicos utilizados neste trabalho tiveram um teor de ferrita superior a $65 \%$. Portanto, pode-se afirmar que esse efeito está relacionado ao metal de adição que possui alto teor de elementos ferritizantes tais como cromo e molibdênio.

A micrografia da zona termicamente afetada (ZTA) pode ser observada na Figura 4. Com a diminuição do aporte térmico, obteve-se uma menor região de ZTA, o que ocasionou uma diminuição do tamanho de grão austenítico. As porcentagens de ferrita e austenita encontradas na ZTA dos diferentes corpos de prova são apresentadas na Tabela 6.

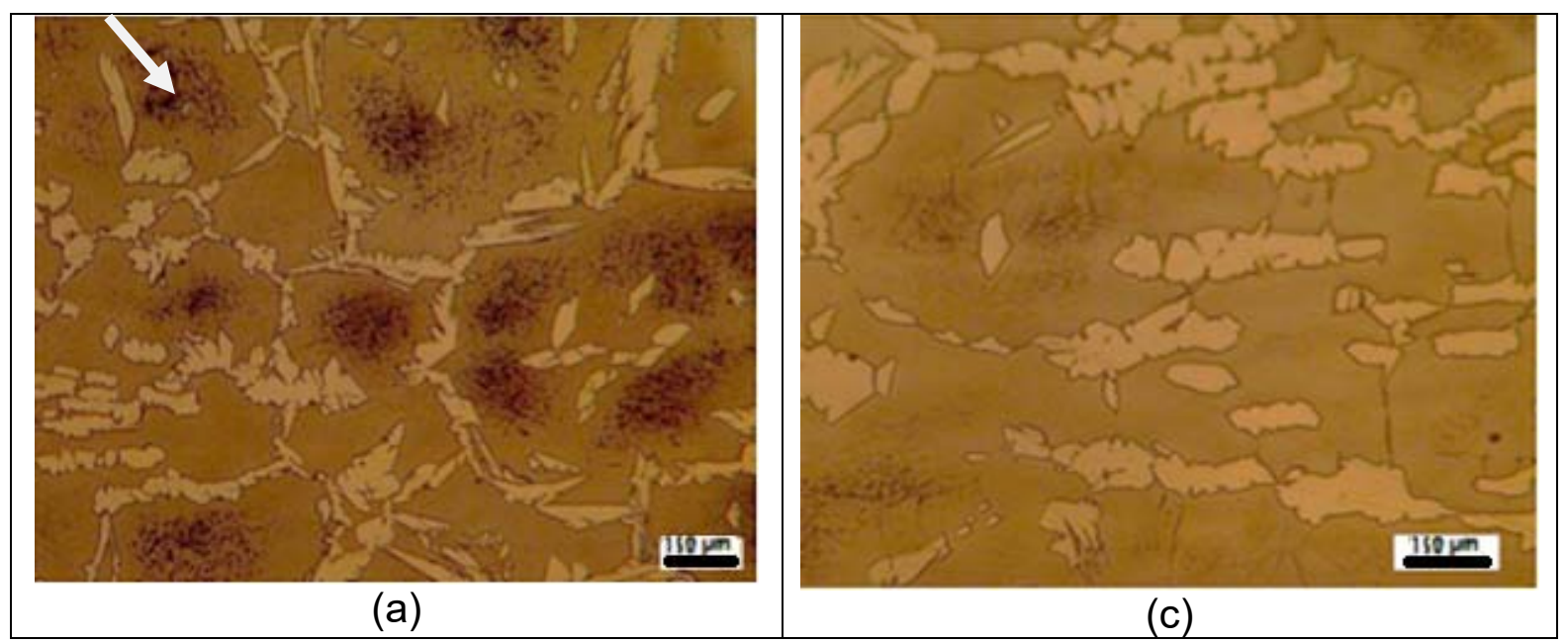




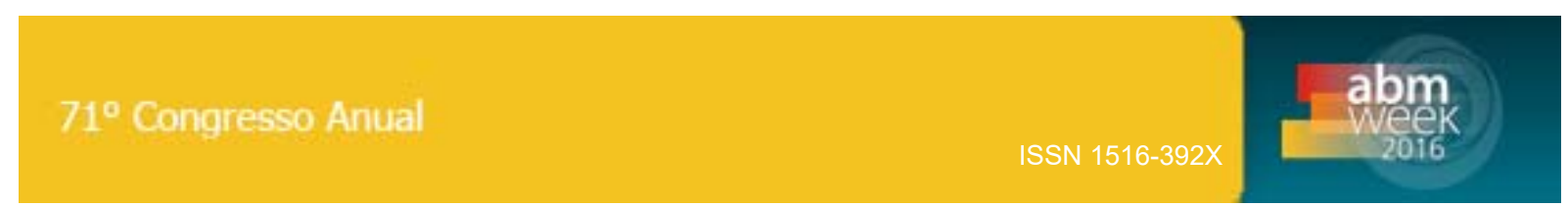

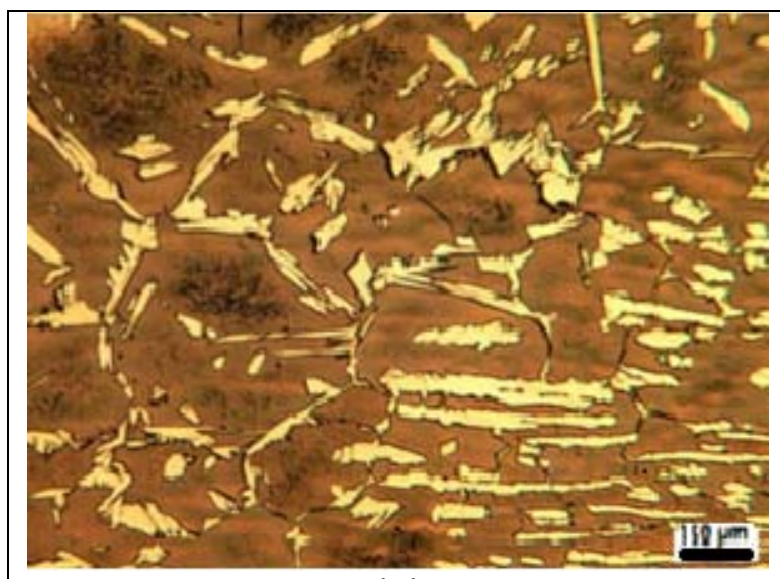

(b)

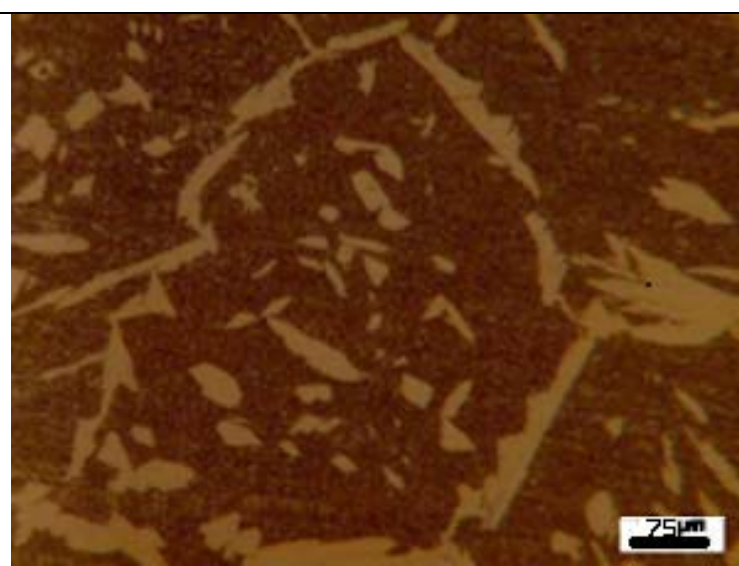

(d)

Figura 4. (a) Zona afetada pelo calor da amostra 1 amplitude de $150 \mu \mathrm{m}$,(b) Zona afetada pelo calor da amostra $2 \mathrm{com}$ amplitude de $150 \mu \mathrm{m}$,(c) Zona afetada pelo calor da amostra $4 \mathrm{com}$ amplitude de $75 \mu \mathrm{m}$ e (d) Zona afetada pelo calor da amostra $8 \mathrm{com}$ amplitude de $75 \mu \mathrm{m}$.

A microestrutura acima revela que com o maior aporte térmico observamos essencialmente um tamanho de grão elevado. É possível notar que uma pequena quantidade de austenita está presente em alguns contornos de grão. Portanto a força motriz para a formação de partículas de austeníta durante o resfriamento é um maior tempo em temperatura superior a $1000^{\circ} \mathrm{C}$ na amostra com maior aporte térmico [14].

Tabela 6. Fração volumétrica de ferrita e austenita das amostras soldadas com diferentes aportes térmicos na zona afetada pelo calor.

\begin{tabular}{|c|r|r|}
\hline $\begin{array}{c}\text { Aporte } \\
\text { térmico(KJ/mm) }\end{array}$ & Austenita & Ferrita \\
\hline 0,74 & 17,9 & 82,1 \\
\hline 1,09 & 18,1 & 81,9 \\
\hline 1,32 & 19,9 & 80,1 \\
\hline 1,87 & 19,8 & 80,2 \\
\hline
\end{tabular}

No resfriamento dos AID, parte da ferrita é transformada em austenita primária. Caso esse resfriamento seja muito rápido, a formação da austenita primaria pode ser prejudicada, obtendo-se uma microestrutura metaestável com elevados teores de ferrita ou da austenita secundária. A austenita secundária pode precipitar a partir da ferrita ou da austenita primaria durante a soldagem [15]. Na Figura 4, a austenita secundaria no interior do grão é indicada pela seta.

$\mathrm{Na}$ amostra soldada com aporte térmico de $1,87 \mathrm{KJ} / \mathrm{mm}$ foi encontrada uma maior quantidade de finas partículas aciculares de austenita secundária do que nas outras amostras. Desta forma, pode-se atribuir essa maior quantidade de austenita secundaria ao maior tempo de difusão. A literatura relata que o processo de nucleação e crescimento desta austenita acicular apresenta uma cinética de transformação do tipo "curva em C", o que sugere que a transformação é controlada por difusão [16].

Com o maior aporte térmico aplicado, a precipitação da fase austenítica ocorreu de forma intensa tanto na região de contorno de grão como também na região central do grão. Com a progressiva diminuição do aporte térmico, a fase austenítica precipitou-se preferencialmente na região de contorno de grão. Isto ocorre devido à 
diminuição do tempo de resfriamento, desta forma, não há tempo suficiente para a formação da austenita na região central do grão [6].

\section{CONCLUSÃO}

Neste trabalho foi realizada a soldagem sobre uma chapa de aço inoxidável UNS S32304 pelo processo GMAW com os diferentes aportes térmicos. A caracterização de regiões tais como metal de base, zona fundida e zona termicamente afetada permite as seguintes conclusões:

a) $\mathrm{Na}$ zona fundida, o aumento do aporte térmico proporcionou uma maior precipitação da austenita com morfologia de widmansttaten.

b) Na zona termicamente afetada. Pode-se concluir que a variação do aporte térmico influenciou de forma pouco significativa a variação das frações volumétricas de ferrita e austenita.

c) A precipitação de fase sigma não foi encontrada em nenhuma das amostras estudadas neste trabalho. Isto pode ser explicado devido ao pouco tempo em que as amostras foram expostas a faixa de temperatura de formação da fase sigma.

d) Os resultados obtidos sugerem que a amostra soldada com aporte térmico de $1,87 \mathrm{KJ} / \mathrm{mm}$ permaneceu mais tempo na faixa de temperatura entre $1300^{\circ} \mathrm{C} \mathrm{e}$ $1400^{\circ} \mathrm{C}$, portanto, tendo maior fração volumétrica de austenita [7].

e) Todas as condições de soldagem nesse trabalho apresentaram uma fração de ferrita superior a $65 \%$.

\section{Agradecimentos}

À CAPES, ao CNPq e à FAPERJ pelo apoio financeiro.

\section{REFERÊNCIAS}

1 Gosh,S.K.;Mondal, S., High temperature ageing behaviour of a duplex stainless steel, ELSEVIER, abr.2008.

2 Souza, G.C.;Pardal, J.M.; Tavares, S.S.M. et al., Avaliação da Proporção de Fases em Juntas Soldadas de Tubulações de Aço Inoxidável Duplex Mediante Aplicação de Ensaios Não Destrutivos, soldagem elnspeção, V.18, n.02, p.158-168, Abril. 2013.

3 Berecz, T.; Szabo, P.J., Crystallographic relations during decomposition of the ferritic phase by isothermal ageing of duplex stainless steel. Journal of Applied Crystallography, vol.46, p.135-141,2013.

4 Tavares, S.S.M.; Pardal, J.M;Guerreiro, J.L. et al.,Magnetic detection of sigma phase in duplex stainless steel UNS S31803,Journal of Magnetism and Magnetic Materials, v.322,L29-L33. 2010.

5 Zamprogno E. B; Rocha Y. S. M. ; Luz, T. S. ,influência da variação da energia de soldagem na formação da microestrutura do aço uns s32304, VI national congress of mechanical engineering ,agosto, 2010.

6 Aguiar, I.V; Escobar, D.P. et al., Microstructure characterization of a duplex stainless steel weld by electron backscattering diffraction and orientation imaging microscopy techniques, Revistamateria, v.20, n.01,p.212-226, Set.2014.

7 Badji, R.; Bouabdallah, M.; Bacroix, B. et al., Phase transformation and mechanical behaviorin annealed 2205 duplex stainless steel welds, Materials Characterization, v.59, n.4, p. 447-453, Abril.2008. 
8 Koussy, M.R.; Mahallawi, I.S.; Khalifa, W. et al., Effects of thermal aging onmicrostructure and mechanical properties of duplex stainless steel weldments, Materials Science andTechnology, v.20, n.3, p. 375-381, Mar.2004.

9 Chan, K. W. ; Tjong, S. C, Effect of Secondary Phase Precipitation on the Corrosion Behavior of Duplex Stainless Steels, Materials, v.7, p. 5268-5304, Jul.2014.

10 Bhadeshia, H. K. D. H. et al. The austenite grain structure of low-alloy steel weld deposits. JournalofMaterials Science, v. 23, pp. 3947-3951, 1986.

11 Chen, T. H.; Yang, J. R. Microstructural characterization of simulated heat affected zone in a nitrogen-containing 2205 duplex stainless steel. Materials Science and Engineering A338 166-181, 2002.

12 Nunes, E. B.; Batista, H. J.; Barreto, A. S. et al.Influência da Energia de a na Microestrutura e na Microdureza de Revestimentos de Aço Inoxidável Duplex, Soldagem e inspeção, v. 17, n.2 , p. 114-122, Abril . 2012

13 Nunes, E. B.; Batista, H. J.; Barreto.Efeito da Energia de Soldagem sobre a Microestrutura e Propriedades Mecânicas da Zona Afetada pelo Calor deJuntas de Aço Inoxidável Duplex, Soldagem e inspeção, v.16,n. 3, p. 223-231, julho. 2010.

14 Shewmon, P.G.; Transactions of the metallurgical society of AIME, New York, v.233, p. 736-748.1965.

15 Londono, A. J. R. Precipitação de fases intermetálicas e austenita secundária na ZAC de soldagens multipasse de aços inoxidáveis duplex. Tese (Doutorado) Departamento de Eng. Metalúrgica, Escola Politécnica, U. de São Paulo, São Paulo, 2001.

16 Távara, S. A. et al. Influence of nickel on the susceptibility to corrosion fatigue of duplex stainless steel welds. International Journal of Fatigue 23 619-626, 2001. 